\title{
Influence of Alveolar Bone Loss and Cement Layer Thickness on the Biomechanical Behavior of Endodontically Treated Maxillary Incisors: A 3-dimensional Finite Element Analysis
}

\author{
Amanda Maria de Oliveira Dal Piva, DDS, MSc, ${ }^{*}$ João Paulo Mendes Tribst, DDS, MSc, * \\ Rodrigo Othávio de Assunção e Souza, DDS, MSc, PbD, ${ }^{+}$ \\ and Alexandre Luiz Souto Borges, DDS, MS, PbD*
}

\begin{abstract}
Ahstract
Introduction: In order to understand the mechanical behavior of a weakened incisor, this study aimed to evaluate the stress distribution caused by different alveolar bone heights and cement layer thickness. Methods: A finite element analysis was conducted for this investigation. An intact maxillary central incisor was initially modeled, and the bone of the models was modified in order to simulate 4 levels of bone height: BL0 (no bone loss), BL1 (1/3 bone loss), BL2 (1/2 bone loss), and BL3 (2/3 bone loss). These teeth models were remodeled with a fiber post at 2 different cement thicknesses and restored with a ceramic crown; " $A$ " refers to the well-adapted fiber post $(0.3 \mathrm{~mm})$ and " $B$ " to the nonadapted fiber post $(1 \mathrm{~mm})$, resulting in 12 models. RelyX ARC (3M ESPE, St Paul, MN) cement was simulated for the cementation of the crowns and fiber posts for all groups. Numeric models received a load of $100 \mathrm{~N}$ on the lingual surface. All materials and structures were considered linear elastic, homogeneous, and isotropic. Numeric models were plotted and meshed with isoparametric elements, and results were expressed in maximum principal stress. Results: For fiberglass posts, cement, and dentin, the highest stress concentration occurred in the groups with increased bone loss. For cortical bone, the highest values were for the groups with $1 / 3$ bone loss. A greater thickness of cement layer concentrates more stress. Conclusions: More bone loss and greater CLT were the influential factors in concentrating the stress. ( $J$ Endod 2017:43:791-795)
\end{abstract}

\section{Key Words}

Alveolar bone loss, dental prosthesis, finite element analysis, post and core technique
In order to restore endodontically treated teeth with little remaining tooth structure, it is better to use fiberglass or carbon fiber posts because of the lower risk of catastrophic failure and better stress distribution compared with metallic posts (1). Retention and stability are directly associated to the success of teeth restored with posts (2). However, in order to guarantee good bonding between fiber posts and root dentin, an adequate cementation strategy is necessary (3). Both conventional and self-adhesive resin cements can be used with confidence for luting fiber-reinforced composite posts (FRCPs) to root dentin, even in areas of significant alveolar bone resorption (3). Cement layer thickness (CLT) can be an important factor to influence bond strength (4). Research has studied the influence of CLT on bond strength (4-6) and found better adhesion associated with a thinner cement layer (6).

Considering teeth with alveolar bone loss, the type of intraradicular post can interfere in the longevity of the restoration treatment, increasing the risk of fracture in coronal dentin because of the promotion of different stress levels, and may also influence bond strength between the FRCP and root dentin (1), thereby increasing the risk of failure when subjected to masticatory loads $(7,8)$. Interfacial characteristics and the elastic modulus of the materials strongly influence the biomechanical behavior (9). When restoring fragile roots, FRCPs present a lower risk of catastrophic failure because of an elastic modulus close to the dentin that promotes a more homogeneous stress distribution compared with metallic posts (1).

Some studies have used finite element analysis (FEA) to evaluate the biomechanical behavior of a restored tooth in the following situations: different restoring configurations $(9,10)$, different fiber post diameters $(11)$, cement types $(12,13)$, post types $(1,14-17)$, and alveolar bone levels $(8,15,16,18)$. However, the interaction of CLT and the alveolar bone level (eg, caused by a periodontal disease) in the biomechanical behavior is still undefined (19). This study aimed to evaluate the stress distribution caused by different alveolar bone heights and CLT in an endodontically treated incisor.

From the *Department of Dental Materials and Prosthodontics, São Paulo State University (Unesp), Institute of Science and Technology, São José dos Campos, São Paulo, Brazil; and ${ }^{\dagger}$ Division of Prosthodontics, Department of Restorative Dentistry, Federal University of Rio Grande do Norte, Natal, Brazil.

Address requests for reprints to Dr Rodrigo Othávio de Assunção e Souza, Division of Prosthodontics, Department of Restorative Dentistry, Federal University of Rio Grande do Norte, Health Center Science, Av Salgado filho, 1787, Lagoa Nova, Natal, RN, Brazil 59.056-000. E-mail address: roasouza@yahoo.com.br 0099-2399/\$ - see front matter

Copyright () 2017 American Association of Endodontists.

http://dx.doi.org/10.1016/j.joen.2016.11.020 


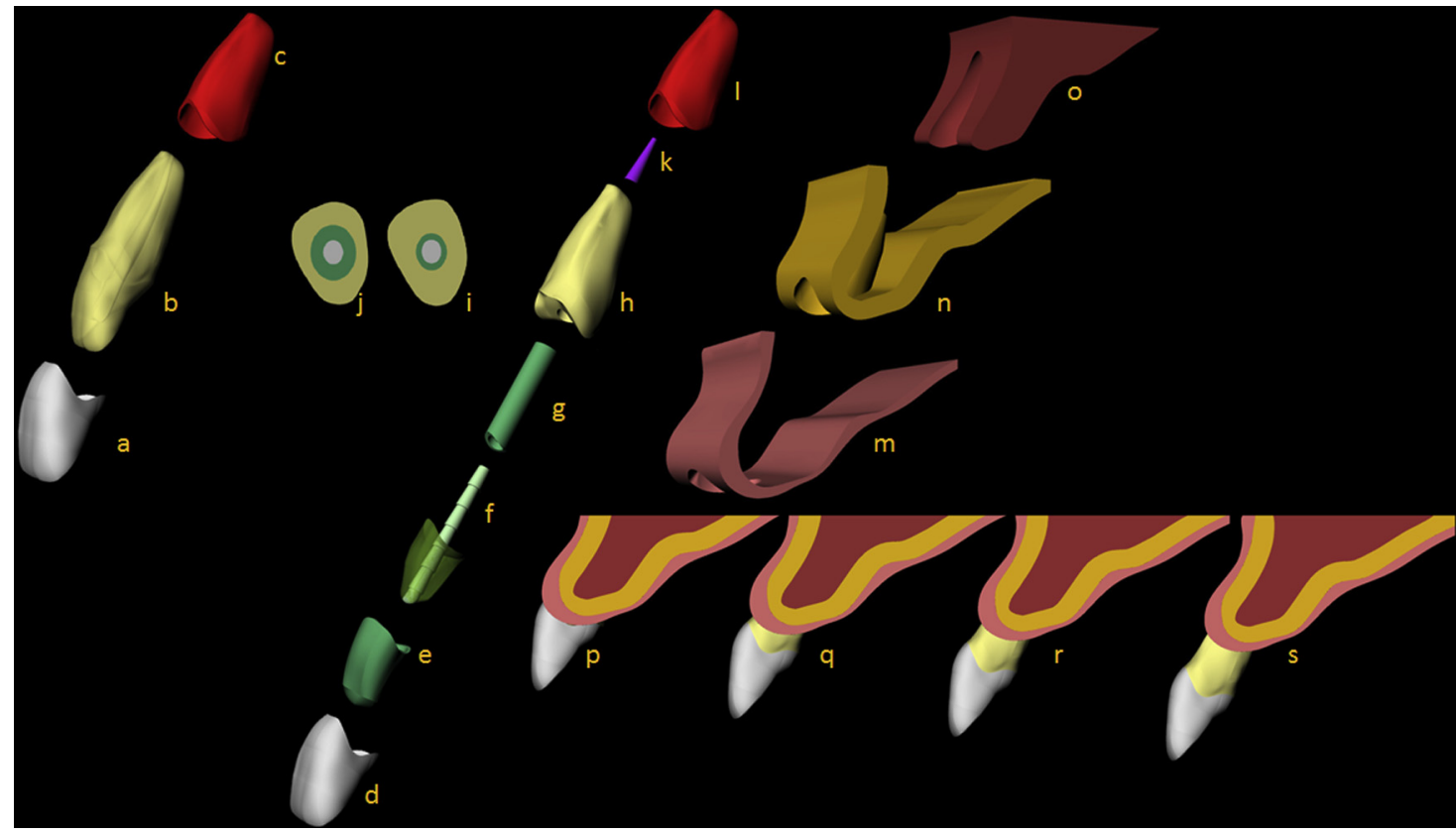

Figure 1. $(a-s)$ A schematic illustration of the sequentially performed procedures. $(a-c)$ A schematic illustration of' a salutary incisor. (a) Enamel, $(b)$ dentin, and $(c)$ periodontal ligament. $(d-l)$ A schematic illustration of an incisor restored with a fiber composite resin post. $(d)$ Ceramic crown, $(e)$ resin cement, $(f)$ core and fiber post, $(g)$ resin cement, and $(b)$ dentin. $(i$ and $j)$ A respective illustration of 0.3 and $1.0 \mathrm{~mm}$ of CLT. ( $k$ ) Gutta-percha, $(l)$ periodontal ligament, $(m)$ gums, $(n)$ cortical bone, and $(o)$ medullar bone. $(p-s)$ Different levels of bone insertion. $(p)$ No bone loss and $(q-s) 1 / 3,1 / 2$, and $2 / 3$ bone loss, respectively.

The null hypothesis of this study was bone loss does not change the biomechanical behavior and cement thickness does not affect the stress profile.

\section{FEA}

\section{Materials and Methods}

This study was conducted using a 3-dimensional (3D) FEA method and specific software (ANSYS 15.0; ANSYS Inc, Houston, TX) to perform a structural mechanical analysis. Schematic illustrations of the performed procedures are shown in Figure 1.

\section{Preprocessing}

A 3D FEA mathematical model simulating an intact maxillary incisor tooth with supporting tissues was created using CAD Rhinoceros (version 4.0SR8; McNeel North America, Seattle, WA) (Fig. 1a-c). Alveolar bone and periodontal ligament dimensions followed average

TABLE 1. Group Distribution according to the Following Factors: Cement Layer Thickness and Bone Loss, Number of Nodes, and Tetrahedral Solid Elements (TSEs)

\begin{tabular}{lcccc}
\hline Group & Cement layer & Bone loss & Node & TSE \\
\hline Ctr0 & - & 0 & 223.229 & 124.114 \\
Ctr1 & - & $1 / 3$ & 215.925 & 120.579 \\
Ctr2 & - & $1 / 2$ & 211.034 & 118.052 \\
Ctr3 & - & $2 / 3$ & 209.267 & 117.190 \\
A0 & $0.3 \mathrm{~mm}$ & 0 & 234.108 & 128.974 \\
A1 & $0.3 \mathrm{~mm}$ & $1 / 3$ & 227.236 & 125.748 \\
A2 & $0.3 \mathrm{~mm}$ & $1 / 2$ & 222.257 & 123.156 \\
A3 & $0.3 \mathrm{~mm}$ & $2 / 3$ & 220.506 & 122.305 \\
B0 & $1 \mathrm{~mm}$ & 0 & 237.618 & 131.087 \\
B1 & $1 \mathrm{~mm}$ & $1 / 3$ & 230.528 & 127.705 \\
B2 & $1 \mathrm{~mm}$ & $1 / 2$ & 225.689 & 125.215 \\
B3 & $1 \mathrm{~mm}$ & $2 / 3$ & 225.689 & 125.215 \\
\hline
\end{tabular}

A, well-adapted fiber post $(0.3 \mathrm{~mm})$; B, nonadapted fiber post $(1 \mathrm{~mm})$; Ctr, control. human anatomy. The periodontal ligament modeled on the tooth root had a thickness of $0.30 \mathrm{~mm}$ (20). This model was created for the control group (intact teeth) with 4 alveolar bone heights (BL0, BL1, BL2, and BL3). Then, 8 more models were created from simulating alveolar bone loss ( 4 levels $[0,1 / 3,1 / 2$, and 2/3]) and CLT (2 levels [0.3 or $1 \mathrm{~mm}]$ ) as described in Table 1 .

A root canal was modeled with the last $4 \mathrm{~mm}$ filled with guttapercha and $11 \mathrm{~mm}$ prepared with a standardized diameter of $3.5 \mathrm{~mm}$ (1). The cement layer was created occupying the entire space between the post and dentin with $0.3-\mathrm{mm}$ thickness (4). The groups with the larger prepared conduct had all regions simulating a weakened root (Fig. $1 d$ - $l$ ) using $1.0 \mathrm{~mm}$ (21) of CLT in all regions with a lower amount of dentin. A 3D human maxilla (São Paulo State University Database, Institute of Science and Technology, São José dos Campos, São Paulo, Brazil) was used to assist the bone tissue model. Two sagittal cuts were performed in order to obtain an isolated anterior area. The external surface was redesigned to remove the anatomic variations of the alveolar process. In the lateral view, the bone was divided into cortical and medullar sections and then separated into 2 juxtaposed geometries (Fig. 1m-o). The hard lamina was individualized for each

TABLE 2. Distribution of the Mechanical Properties of the Materials

\begin{tabular}{lccc}
\hline Structure/material & $\begin{array}{c}\text { Elastic modulus } \\
(\mathrm{GPa})\end{array}$ & $\begin{array}{c}\text { Poisson } \\
\text { ratio }\end{array}$ & Reference \\
\hline Enamel & 84.1 & 0.33 & $(15)$ \\
Dentin & 18.6 & 0.32 & $(12)$ \\
Ligament & 0.069 & 0.45 & $(16,22)$ \\
Gingiva & 0.003 & 0.45 & $(16)$ \\
Cortical bone & 13.7 & 0.30 & $(12)$ \\
Spongy bone & 1.37 & 0.30 & $(12)$ \\
RelyX ARC & 5.1 & 0.27 & $(8)$ \\
Gutta-percha & 0.69 & 0.45 & $(16)$ \\
Fiberglass post & 49 & 0.28 & $(16)$ \\
Lithium disilicate & 95 & 0.3 & $(23)$ \\
\hline
\end{tabular}




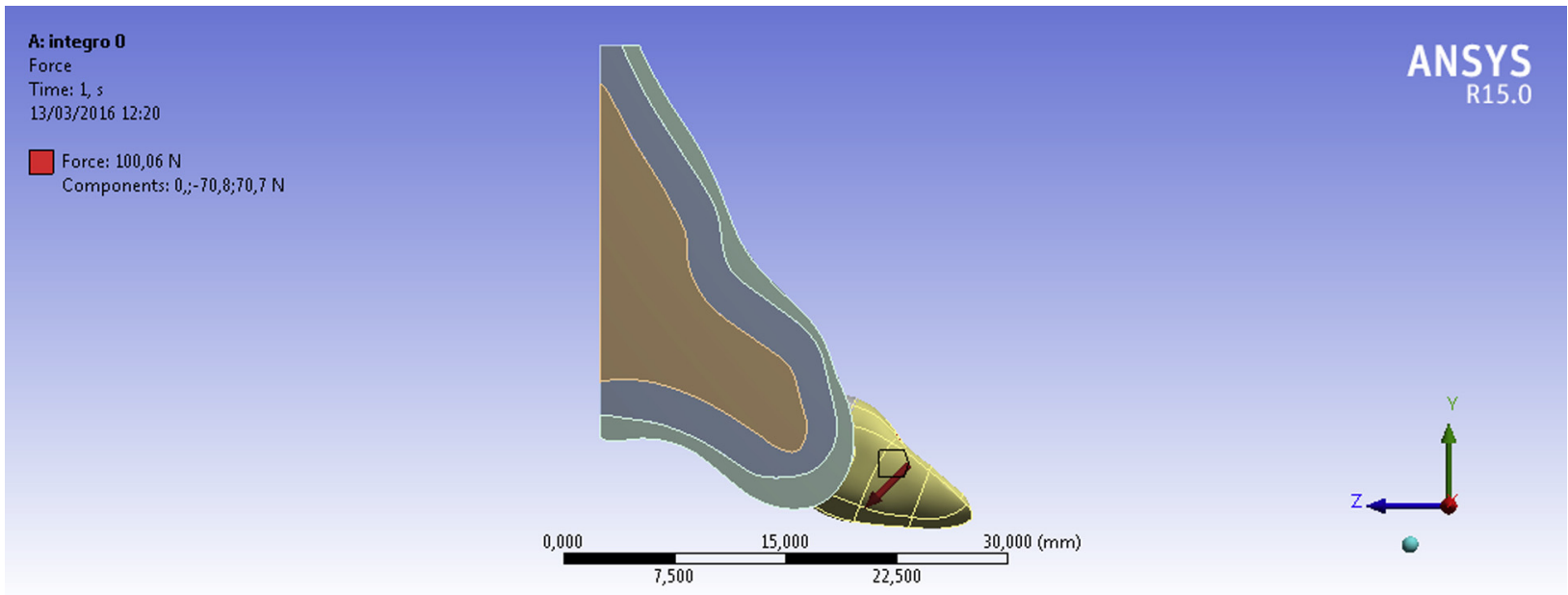

Figure 2. A static load of $100 \mathrm{~N}$ was applied to the contact area on the lingual surface $\left(45^{\circ}\right)$.

model of bone tissue in order to follow the amount of inserted periodontal ligament. Bone height was modeled with $1 / 3,1 / 2$, and $2 / 3$ (Fig. $1 p-s$ ) of insertion loss from the initial model without bone loss (0). Lithium disilicate (Emax CAD, Schaan, Liechtenstein) full crowns were cemented to the models, except in the control groups.

Solids were exported in STEP format to the software for analysis, and mesh was created with tetrahedral quadratic elements. Each mathematical model included a different number of nodes (223.591) and tetrahedral solid elements (124.112). Exterior nodes of jaw structure models were fixed in all directions as the boundary condition. All materials were considered isotropic, linear, and homogenous. Corresponding elastic properties, such as the Young modulus (E) and Poisson ratio, were determined from the literature (Table 2) $(9,13,16,17,22,23)$.

A 100-N static load was applied to the contact area on the lingual surface of the crown (17) with a $45^{\circ}$ from the tooth's longitudinal axis $(13,22)$ for calculating stress distributions (Fig. 2). The results of the stress distributions are presented in graphics with a color scale in megapascals. Von Mises stress is a common failure criteria that shows the energy transmission in the structure $(1,17,24)$. However, the maximum principal stress (MPS) was conducted in the present study to discriminate the compressive and tensile stress fields.

\section{Results}

Stress distribution in dentin is shown in Figure $3 A-L$. It is possible to observe (through the red color) that tensile stress (the opposite side of load application) in dentin is proportional to increased bone loss. As shown in Figure 3 and Table 3, the higher MPSs in dentin were observed in the control group with 2/3 alveolar bone loss height (BL3) and the lowest stress in an incisor restored with a fiberglass post and with a thinner cement layer $(0.3 \mathrm{~mm})$ without alveolar bone loss height (A0). In the same figure, it is possible to observe that there is proportionality between the different bone levels and stress concentration in dentin. Other structures showed the same behavior, except for the cement layer in the $\mathrm{A} 0$ and $\mathrm{A} 1$ groups and the cortical bone in the B2 and B3 groups (Table 3). The control group showed the highest value for stress on dentin increased by alveolar bone loss. However, the authors suggest that the control group cannot be considered the worst group. Endodontically treated incisors not only presented stress concentration in dentin but also in fiber posts and cement layers.

\section{Discussion}

The first hypothesis that biomechanical behavior changes with bone loss was accepted and the second that CLT does not affect the stress profiles was rejected. FEA has the advantage of being identical for all the models used, which is not repeatable in laboratory studies (16). Therefore, FEA is a useful tool for preclinical assessment (25) because of standardized roots and symmetrically inserting the fiber post to the cement film. This research showed significant changes in the stress distribution on the cement layer from its thickness. For cortical bone, the highest values of MPS were in situations of $1 / 3$ bone loss, accepting the first null hypothesis. MPS values on cement layer increased $120 \%, 194 \%, 240 \%$, and $226 \%$, respectively, to improved bone loss $(0,1 / 3,1 / 2$, and $2 / 3 \mathrm{~mm})$, thereby rejecting the second hypothesis.

The stress distribution pattern in intact natural teeth is different from teeth restored with dental post system. An intact tooth can flex during functional load, whereas a restored tooth with a dental post system shows regions of shear stress concentration occurring at the post and cement/dentin interfaces (13).

Change in fulcrum occurs generated by bone loss, which causes a decrease of stress values on the vestibular bone plate after the first reduction of bone insertion. However, noting the stress values generated on the 4 studied points (Table 3), there is an increase of stress across the cortical structure. Therefore, the increase in bone loss does not decrease the damage in the vestibular tissue but distributes it around the bone, potentially injuring other regions.

Stress concentration in the fiber post decreased with greater thickness of the cement line. The low modulus of the cement agent could be acting as a retainer factor of loads. However, tension accumulation in the cement line may be more harmful than beneficial to the restoration. Twenty-seven (26) megapascals was identified in the cement layer (being within the limitations of this study), which consists of ideal contact and materials working within the elastic limit. Therefore, stress concentration in the cement layer can promote adhesive failures as observed in laboratory studies $(3,26,27)$. Adhesive failure on the cement/dentin interface is very common because the critical stress of the cement is less than that compared with a fiber post or tooth structure. For example, a 27-MPa load on the cement is much closer to a failure occurring than $27 \mathrm{MPa}$ in the fiber post. An FRC post that is well adapted to the root canal results in higher bond strength values, thus improving post retention (2). However, there is an importance in studying whether it 


\section{Basic Research-Technology}
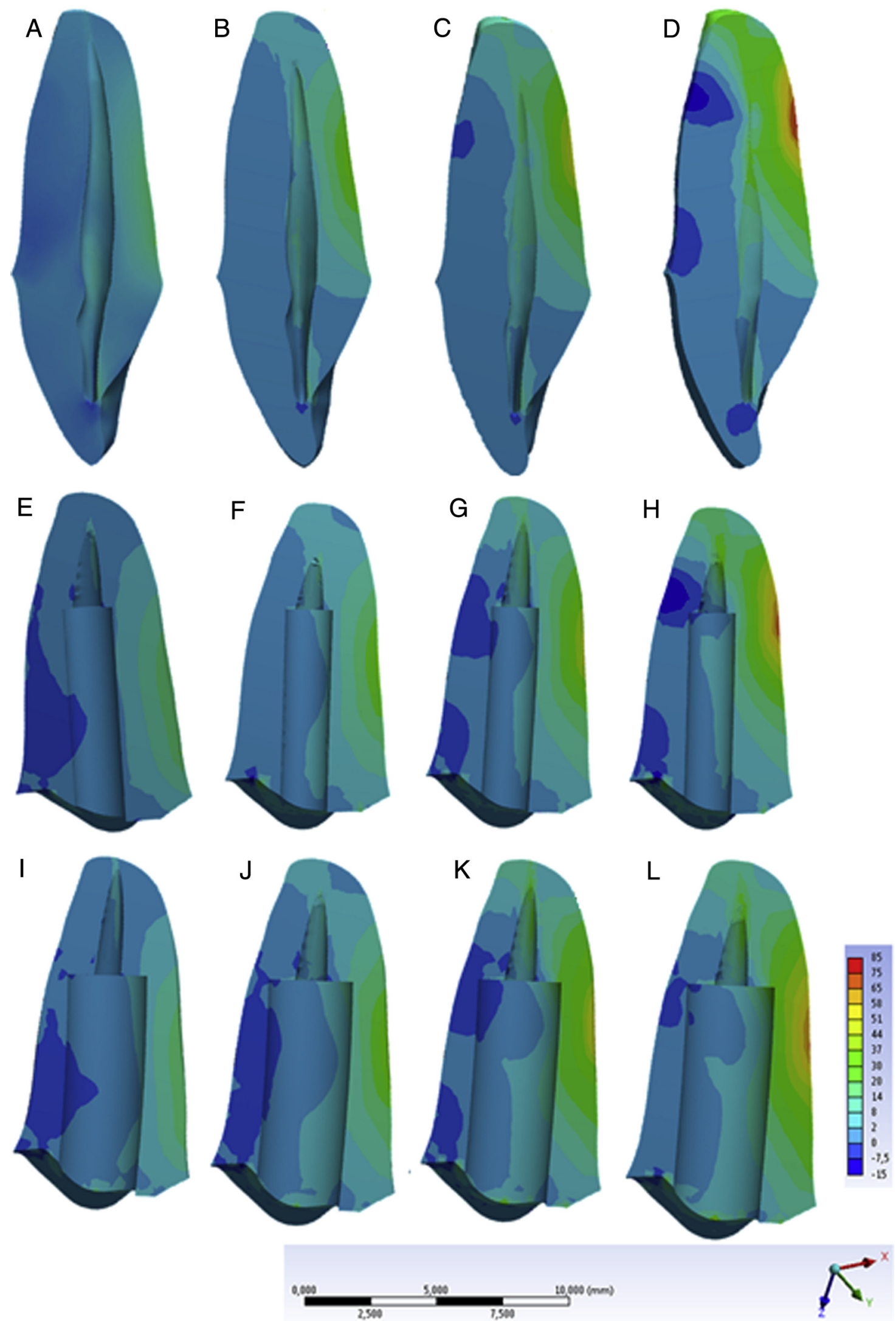

Figure 3. Stress distribution in dentin according to alveolar bone loss: 0 (no bone loss), 1/3,1/2, and 2/3 of bone loss, respectively, from the left to the right. ( $A-D$ ) Salutary incisor, $(E-H)$ endodontically treated teeth restored with a fiber post and $0.3 \mathrm{~mm}$ of cement layer thickness, and $(I-L)$ endodontically treated teeth restored with a fiber post and $1 \mathrm{~mm}$ of cement layer thickness. The red color corresponds to tensile stress, whereas blue corresponds to compression. 
TABLE 3. Distribution of Data (MPa) of the Maximum Principal Stress in the Fiber Post, Cement Layer, Dentin, Cortical Bone, and 4 Different Areas of the Cortical Bone: Vestibular (V), Buccal (B), Mesial (M), and Apical (A)

\begin{tabular}{|c|c|c|c|c|c|c|c|c|}
\hline Group & Fiber post & Cement layer & Dentin & Cortical bone & V & B & M & $A$ \\
\hline BLO & - & - & 23.287 & 33.805 & 31.48 & 7.72 & 4.02 & 0.79 \\
\hline BL1 & - & - & 35.714 & 94.132 & 87.65 & 9.52 & 4.22 & 2.11 \\
\hline BL2 & - & - & 56.043 & 75.595 & 72.31 & 13.35 & 6.14 & 5.28 \\
\hline BL3 & - & - & 81.17 & 69.356 & 64.83 & 29.88 & 8.13 & 7.81 \\
\hline AO & 16.23 & 8.10 & 20.894 & 33.285 & 29.80 & 7.27 & 3.37 & 0.97 \\
\hline A1 & 24.064 & 7.68 & 43.308 & 92.075 & 78.42 & 11.11 & 4.01 & 3.02 \\
\hline$A 2$ & 40.287 & 9.17 & 51.293 & 73.776 & 71.72 & 11.88 & 5.23 & 3.91 \\
\hline A3 & 50.206 & 11.965 & 73.561 & 66.695 & 9.96 & 27.30 & 65.74 & 8.05 \\
\hline BO & 17.215 & 9.75 & 21.852 & 33.307 & 31.65 & 7.34 & 3.98 & 0.97 \\
\hline B1 & 21.515 & 14.914 & 35.983 & 92.603 & 73.75 & 10.16 & 3.95 & 2.78 \\
\hline B2 & 37.984 & 22.061 & 54.447 & 73.723 & 66.37 & 14.06 & 4.91 & 3.74 \\
\hline B3 & 40.118 & 27.098 & 71.931 & 86.651 & 80.70 & 15.87 & 6.05 & 5.40 \\
\hline
\end{tabular}

A, well-adapted fiber post $(0.3 \mathrm{~mm})$; B, nonadapted fiber post $(1 \mathrm{~mm})$.

is better to use a lower thickness of cement with a higher elastic modulus or a higher thickness of cement with a lower elastic modulus. Consequently, this layer could distribute the stress more homogeneously. From these results, it is necessary to conduct more studies to clarify why there is no proportionality between the thinner cement layer in groups A0 and A1 and the cortical bone for the B2 and B3 groups with a larger cement layer.

Regarding clinical implications, a weakened root that has to receive an FRCP and presents alveolar bone loss is encouraged to be restored with a well-adapted FRCP. Nevertheless, it is important to mention that the stress in the cement layer increases with increasing bone loss independent of CLT, which can promote future adhesive failure.

\section{Conclusion}

Within the limitations of this FEA study, it is possible to ascertain that bone loss is a facilitating factor for stress concentration on the fiber post, cement thickness, and remaining dentin, which suggests more probability for these restorations to fail. Moreover, a thicker cement layer does not have the tendency to concentrate stress in the tooth structure but instead in the fiber post, suggesting a lower risk of cementation failure.

\section{Acknowledgments}

The authors deny any conflicts of interest related to this study.

\section{References}

1. Coelho CS, Biffi JC, Silva GR, et al. Finite element analysis of weakened roots restored with composite resin and posts. Dent Mater J 2009;28:671-8.

2. Penelas AG, Piedade VM, Borges AC, et al. cement film thickness influence bond strength and fracture resistance of fiber reinforced composite posts? Clin Oral Investig 2016;20:849-55.

3. Dal Piva AM, Campos F, Alves ML, et al. Influence of alveolar bone level on the pullout bond strength of fiber-reinforced composite posts to root dentin. Gen Dent 2016;64:e5-8.

4. D'Arcangelo C, Cinelli M, De Angelis F, D'Amario M. The effect of resin cement film thickness on the pullout strength of a fiber-reinforced post system. J Prosthet Dent 2007:98:193-8.

5. Egilmez F, Ergun G, Cekic-Nagas I, et al. Influence of cement thickness on the bond strength of tooth-colored posts to root dentin after thermal cycling. Acta Odontol Scand 2013;71:175-82.

6. Gomes GM, Rezende EC, Gomes OM, et al. Influence of the resin cement thickness on bond strength and gap formation of fiber posts bonded to root dentin. J Adhes Dent 2014;16:71-8.

7. Komada W, Miura H, Okada D, Yoshida K. Study on the fracture strength of root reconstructed with post and core: alveolar bone resorbed case. Dent Mater J $2006 ; 25: 177-82$

8. Naumann M, Rosentritt M, Preuss A, Dietrich T. The effect of alveolar bone loss on the load capability of restored endodontically treated teeth: a comparative in vitro study. J Dent 2006;34:790-5.
9. Zarone F, Sorrentino R, Apicella D, et al. Evaluation of the biomechanical behavior of maxillary central incisors restored by means ofendocrowns compared to a natural tooth: a 3D static linear finite elements analysis. Dent Mater 2006;22:1035-44.

10. Ausiello P, Franciosa P, Martorelli M, Watts DC. Mechanical behavior of post-restored upper canine teeth: a 3D FE analysis. Dent Mater 2011;27:1285-94.

11. Wandscher VF, Bergoli CD, de Oliveira AF, et al. Fatigue surviving, fracture resistance, shear stress and finite element analysis of glass fiber posts with different diameters. J Mech Behav Biomed Mater 2015;43:69-77.

12. Soares CJ, Raposo LH, Soares PV, et al. Effect of different cements on the biomechanical behavior of teeth restored with cast dowel-and-cores-in vitro and FEA analysis. J Prosthodont 2010;19:130-7.

13. Madfa AA, Kadir MR, Kashani J, et al. Stress distributions in maxillary central incisors restored with various types of post materials and designs. Med Eng Phys 2014;36: $962-7$.

14. Lanza A, Aversa R, Rengo S, et al. 3D FEA of cemented steel, glass and carbon posts in a maxillary incisor. Dent Mater 2005;21:709-15.

15. Roscoe MG, Noritomi PY, Novais VR, Soares CJ. Influence of alveolar bone loss, post type, and ferrule presence on the biomechanical behavior of endodontically treated maxillary canines: strain measurement and stress distribution. J Prosthet Dent 2013; 110:116-26.

16. Singh SV, Bhat M, Gupta S, et al. Stress distribution of endodontically treated teeth with titanium alloy post and carbon fiber postwith different alveolar bone height: a three-dimensional finite element analysis. Eur J Dent 2015;9:428-32.

17. Değer Y, Adigüzel Ö, Yiğit Özer $S$, et al. Evaluation of temperature and stress distribution on 2 different post systems using 3-dimensional finite element analysis. Med Sci Monit 2015;21:3716-4172.

18. Belli S, Eraslan O, Eskitascioglu G. Effect of root filling on stress distribution in premolars with endodontic-periodontal lesion: a finite elemental analysis study. J Endod 2016;42:150-5.

19. Souza RO, Alves ML, De Sousa RS, et al. Resin bonding to root dentin: influence of the alveolar bone level and thickness of the cement layer. Minerva Stomatol 2014; 63:239-48.

20. Hohmann A, Kober C, Young P, et al. Influence of different modeling strategies for the periodontal ligament on finite element simulation results. Am J Orthod Dentofacial Orthop 2011;139:775-83.

21. Lazari PC, Oliveira RC, Anchieta RB, et al. Stress distribution on dentin-cement-post interface varying root canal and glass fiber post diameters. A three-dimensional finite element analysis based on micro-CT data. J Appl Oral Sci 2013;21:511-7.

22. Joshi S, Mukherjee A, Kheur M, Mehta A. Mechanical performance of endodontically treated teeth. Finite Elem Anal Des 2001;37:587-601.

23. Ma L, Guess PC, Zhang Y. Load-bearing properties of minimal-invasive monolithic lithium disilicate and zirconia occlusal onlays: finite element and theoretical analyses. Dent Mater 2013;29:742-51.

24. Santos-Filho PC, Veríssimo C, Raposo LH, et al. Influence of ferrule, post system, and length on stress distribution of weakened root-filled teeth. J Endod 2014;40: 1874-8.

25. Verri FR, Cruz RS, de Souza Batista VE, et al. Can the modeling for simplification of a dental implant surface affect the accuracy of 3D finite element analysis? Comput Methods Biomech Biomed Engin 2016;19:1665-72.

26. Daleprane B, Pereira CN, Bueno AC, et al. Bond strength of fiber posts to the root canal: Effects of anatomic root levels and resin cements. J Prosthet Dent 2016;116: 416-24.

27. Tian Y, Mu Y, Setzer FC, et al. Failure of fiber posts after cementation with different adhesives with or without silanization investigated by pullout tests and scanning electron microscopy. J Endod 2012;38:1279-82. 